\title{
Research on Risk Pre-Warning Mechanism under Financial Crisis
}

\author{
Jingting Ma \\ School of Business Administration, Shenyang University \\ Shenyang 110044, China \\ E-mail: ttkklltt@126.com \\ Shumei Wang \\ International Business College, Shenyang University \\ Shenyang 110044, China \\ E-mail: ggg108@sohu.com \\ Jian Gui \\ School of Economics, Shenyang University \\ Shenyang 110044, China \\ E-mail: gweijean@126.com
}

\begin{abstract}
Since 2007, the effects of US sub-prime mortgage crisis are deepening further. The international conductive effect enlarges the global economic risk. World economic conditions tend to be more complicated. At present, the financial crisis is caused by borrowers defaulting contracts, which causes the depression of financial market. Financial crisis turns into a considerable issue in the world. Therefore, based on fully recognizing the importance of financial crisis, we can build a risk pre-warning mechanism to reduce financial crisis, avoiding more losses caused by financial crisis.
\end{abstract}

Keywords: Financial crisis, Risk system, Risk pre-warning

\section{The concept of financial crisis}

\subsection{The definition of financial crisis and the causes}

Financial crisis means the possibilities of capitals, properties, and credits suffering from losses, because of decision mistakes, changes of objective conditions, or other reasons, in the operations of financial institutions. The risk happened in one financial institution may influence more than itself. The financial institution's risk in financial transactions may threat the existence of this financial institution. One financial institution may face the risk caused by bad operations, which can turn into a threat for the stable operation of the whole financial system. Once a systematic risk happens and the financial system is disabled, the whole economic order will in a mess, which even causes serious political crisis.

Main causes of financial crisis include: (1) Borrowers can not fulfill the signed contract for loans; (2) Financial institutions are incapable of paying off; (3) Changes of rates of interests in market; (4) Changes of exchange rate; (5) Improper state macro economic and financial decisions or mistakes; (6) The default operations of top managers in financial institutions; (7) Other countries or regions' political and economic changes; (8) Over use of financial derivatives; (9) Fast development of financial institutions.

\subsection{The characteristics of financial risks in China}

(1) The imbalanced financial structure and the abnormal development of financing make risks center in banks. In China, the development of capital market and small and medium financial institutions lags behind. State-owned banks hold the absolute dominating advantage in capital distribution for a long period.

(2) Financial risks and fiscal risks are enlarged due to the mutual effects. During the gradual reform process, the risk separation mechanism between fiscal and finance is always an absence.

(3) The large-sized informal finance turns into a threat for financial safety. For many years, small and medium enterprises can not get funds for development from formal financial channels. They are forced to seek for informal financial channels. At present, informal finance accounts for one third of formal finance in China. 
(4) In the transformation of mechanism, financial institutions face serious risks. The banking industry is full of risks. The asset quality deserves more cares. Great financial risks lie in the industry of securities. Insurance companies' risks should not be neglected either.

(5) The regulation on capital projects is weak. It may cause abnormal capital flow at a large scale.

(6) Defects in RMB exchange rate mechanism hurt citizens' welfare. It results in that China's traditional opening-up mode and policies fall in non-sustainable development.

(7) Risks of rates of interests are prominent. The marketization of rates of interests is a double-edged sword. Risks of rates of interests are the two sides of same issue in the process of marketization of rates of interests. In China, the marketization process is slow and regulations are very strict. Commercial banks can not adjust the rate of interests by themselves. They face serious systematic risks of rate of interests. Meanwhile, along with the marketization of rates of interests in China, rates of interests fluctuate heavily. However, financial institutions are incapable of managing risks of rates of interests, which may cause higher risks.

(8) Financial risks in real estate industry needs to be noticed, plus the risks, similar to that in Latin America (It refers to a phenomenon: domestic financial activities depend more on international capitals; domestic financial market is gradually taken by foreign funds; domestic asset pricing right, securities service industry, and investment return are mostly controlled or dominated by international investors and foreign financial service institutions), in the opening-up process of finance.

\section{The importance of financial risk issue}

In market economy, all activities face certain risks. Financial risks are more prominent. Based on the most abstract analysis, economic operation system can be divided into two sectors: real economy sector and financial sector. Under modern economic conditions, contradictions in real economy sector may turn into financial risks. Besides, finance may face kinds of risks in operations. Especially as the securitization of assets and the popularization of derivatives become a trend, the independent operations of virtual products may generate more financial risks. Therefore, in a market economy system, financial risks are normal and reasonable.

Financial risks are common. The financial risk issue is extremely important, because:

Firstly, according to lessons from six East Asian countries, Russia, and Brazil, financial risks and instability are based on long-term accumulated financial risks. Once financial risks become financial crises, it will cause economic depression, and trigger social crisis and even political crisis.

Secondly, in China during the economic transition process, state-owned commercial banks' funds are used as "semi-fiscal capitals" for a long period, which are used to support state-owned enterprises. The operation from "budget soft constraint" to "credit soft constraint" turns state-owned enterprises' debts into state-owned commercial banks' bad assets. The large amount of stock bad assets and increasing bad assets turn into "time bombs" that influence economic development.

Thirdly, China economy's external dependence is improving. Under this circumstance, to deal with financial risks may affect two fields. The first is the capability of resisting external financial impacts. The second is the trust of world financial market. Only when we perform structural adjustment, solve and decrease financial risks effectively, can we avoid financial crisis and attract more foreign investors.

\section{Pre-warning for financial risks}

Facing serious financial risks, we can adopt two methods. Firstly, we can prevent risks by building a pre- warning mechanism. Secondly, we can reduce losses after risks are coming. By comparing the two methods, we conclude that the first can defend financial risks better, and the losses will be less.

The so-called financial risk pre-warning means to supply countermeasures and suggestions for financial safety by analyzing and predicting the possibilities in financial operations. Financial risk pre-warning system is an organic body composed by the form, the index system, the prediction methods which are used to reflect financial risks and relevant changes. It is based on economic and financial statistical data, and information technologies. It serves as an important part of state macro control system and financial risk prevention system.

\subsection{Build the financial risk pre-warning system}

\section{(1) Build an internal safety net in financial system}

International Monetary Fund (IMF) has applied the "Financial Sector Assessment Program" since May, 1999, by which it can evaluate the stability of financial system in member countries. China can adopt this system to evaluate the stability of financial system. In Nov. 2003, China Banking Regulatory Commission publicizes a pressure test for commercial banks, which is a component of "Financial Sector Assessment Program". The pressure test means to evaluate financial institutions' risks and potential vulnerability by analyzing the influences of changes of macro 
economic variables on the stability of financial system.

(2) Build a hierarchical pre-warning system

In America, the pre-warning system is hold by independent subjects. According to this mode, in China the financial pre-warning system should take China Banking Regulatory Commission as the subject. China Banking Regulatory Commission can check financial institutions' operational conditions and ask them to supply financial materials. With this basis, we can apply a vertical supervising pre-warning system at the macro, middle, and micro aspects. In detail, China Banking Regulatory Commission and central banks of commercial banks form the macro pre-warning system. Trans-provincial banking regulatory commissions and commercial banks' branches form the regional middle pre-warning system. Commercial banks and local financial institutions form the micro pre-warning system. In detail, the macro pre-warning system is mainly in charge of supervising and pre-warning national and regional financial institutions, managing and directing the middle and macro pre-warning systems, collecting sorts of information from middle and micro pre-warning systems, and offering relevant decisions and measures for preventing financial risks after processing the information. The middle pre-warning system is a regional system that connects with central banks. It is responsible for supervising local financial institutions, accepting China Banking Regulatory Commission's macro pre-warning system's guidance and management, offering supervision and consultation for local financial institutions, and conveying central banks' decisions and measures. The micro pre-warning system is to follow China Banking Regulatory Commission's pre-warning directions, and offer scientific pre-warning information for branches of banks. The three-level pre-warning system constitutes a net system, actualizing a vertical risk supervising and pre-warning.

(3) Perfect the scientific financial pre-warning index system

Assess commercial banks' capital adequacy rate, rate of overdue loans, return of loan interests, capital efficiency, funds efficiency, and general expense rate. The dynamic changes of indexes can reflect commercial banks' assets distribution and risks separation. We can trace possible elements of risks changes, identify pre-warning signals for bad changes, make up practical program for depressing risks, and avoid the emergence and worsen of risks.

\subsection{The difficulties for building a financial risk pre-warning mechanism}

Firstly, an information share mechanism for economy and finance is still an absence. It is hard to start the risk pre-warning without any basis.

The construction of pre-warning mechanism concerns not only the relationship between People's Bank of China and financial regulatory institutions, but also the relationship between People's Bank of China and relevant official economic sectors, such as National Development and Reform Commission, Ministry of Finance, Pricing Agency, and Statistical Agency. However, because functions are different, People's Bank of China and regulatory institutions, People's Bank of China and official agencies can not share information effectively. It can be solved by the information share mechanism. At present, the information share mechanism is still an absence. People's Bank of China can not make full of economical data from regulatory institutions and official agencies. It is hard to communicate financial risk pre-warning information, collect relevant index data, and actualize the supervision and pre-warning for financial risks.

Secondly, financial index data has poor comparability.

The pre-warning task needs to collect index data for several years or even decades of years. And the definition of index and calculation should not be changed. China is at the transition period. Recent economic and financial indexes change a lot comparing with that in middle and late $90 \mathrm{~s}$ in $20^{\text {th }}$ century. For example, commercial banks sort bad assets into five grades. Rural Credit Cooperation sorts bad assets into four grades. For same index, different financial institutions name it differently. Besides, they may adopt different standards. The poor comparability of indexes makes it hard to process data for pre- warning.

\subsection{The countermeasures and suggestions for speeding up the construction of financial risk pre-warning mechanism}

Firstly, speed up the construction and the perfect of economic and financial information share mechanism and insure to collect relevant data in time. In practice, the content of information share mechanism includes financial statistical information, analysis materials, regulatory reports, files, financial notices, information communication, conference communication, and financial information materials retrieve. Besides, we should perfect the information communication mechanism for People's Bank of China and official economic agencies.

Secondly, build a perfect financial data collection system and study and develop a financial risk pre-warning mode. People's Bank of China should make up strict standards for data collection, including the contents, the forms, the ways, the methods, and the channels according to China's conditions, in order to insure the authenticity of data. With this base, use computer technologies to develop the risk pre-warning mode, finding potential financial risks effectively, and realizing the exact, scientific, and effective pre-warning for financial risks.

Thirdly, insure the information safety for financial risk pre-warning. At present, social public are sensitive to the finance industry. People are incapable of facing financial risks. Grapevines way cause a psychological panic among the public, 
which may result in a financial turbulence.

\section{References}

Bai, Shichun. (2004). How the People's Bank of China prevents and settles down systematic financial risks. China Finance, No. 8.

Dong, Xiaojun. (2004). Build an effective financial risk pre-warning mechanism. Financial News. $17^{\text {th }}$, Nov.

Dong, Xiaojun. (2004). Research on Financial Risk Pre-warning Mechanism. Beijing: Economy and Management Publishing House.

Financial Stability Project Team, Nanning Central Branch, The People's Bank of China. (2005). Ideas for building financial risk pre-warning mechanism. South China Finance, No.2.

Jiang, Boke. (2005). International Finance ( $3^{\text {rd }}$ edition). Shanghai: Fudan University Press. 